\title{
Preventable hospitalization and access to primary health care in an area of Southern Italy Paolo Rizza1 ${ }^{1}$ Aida Bianco ${ }^{1}$, Maria Pavia*1 and Italo F Angelillo²
}

\author{
Address: ${ }^{1}$ Chair of Hygiene, Medical School, University of Catanzaro "Magna Græcia", Catanzaro, Italy and ${ }^{2}$ Department of Public, Clinical and \\ Preventive Medicine, Second University of Naples, Naples, Italy \\ Email: Paolo Rizza - igiene@unicz.it; Aida Bianco - a.bianco@unicz.it; Maria Pavia* - pavia@unicz.it; \\ Italo F Angelillo - italofrancesco.angelillo@unina2.it \\ * Corresponding author
}

Published: 30 August 2007

BMC Health Services Research 2007, 7:134 doi:10.1 186/1472-6963-7-134
Received: 20 November 2006

Accepted: 30 August 2007

This article is available from: http://www.biomedcentral.com//472-6963/7//34

(C) 2007 Rizza et al; licensee BioMed Central Ltd.

This is an Open Access article distributed under the terms of the Creative Commons Attribution License (http://creativecommons.org/licenses/by/2.0), which permits unrestricted use, distribution, and reproduction in any medium, provided the original work is properly cited.

\begin{abstract}
Background: Ambulatory care-sensitive conditions (ACSC), such as hypertension, diabetes, chronic heart failure, chronic obstructive pulmonary disease and asthma, are conditions that can be managed with timely and effective outpatient care reducing the need of hospitalization. Avoidable hospitalizations for ACSC have been used to assess access, quality and performance of the primary care delivery system. The aims of this study were to quantify the proportion of avoidable hospital admissions for ACSCs, to identify the related patient's socio-demographic profile and health conditions, to assess the relationship between the primary care access characteristics and preventable hospitalizations, and the usefulness of avoidable hospitalizations for ACSCs to monitor the effectiveness of primary health care.
\end{abstract}

Methods: A random sample of 520 medical records of patients admitted to medical wards (Cardiology, Internal Medicine, Pneumology, Geriatrics) of a non-teaching acute care 717-bed hospital located in Catanzaro (Italy) were reviewed.

Results: A total of $31.5 \%$ of the hospitalizations in the sample were judged to be preventable. Of these, $40 \%$ were for congestive heart failure, $23.2 \%$ for chronic obstructive pulmonary disease, $13.5 \%$ for angina without procedure, $8.4 \%$ for hypertension, and $7.1 \%$ for bacterial pneumonia. Preventable hospitalizations were significantly associated to age and sex since they were higher in older patients and in males. The proportion of patients who had a preventable hospitalization significantly increased with regard to the number of hospital admissions in the previous year and to the number of patients for each primary care physician (PCP), with lower number of PCP accesses and PCP medical visits in the previous year, with less satisfaction about PCP health services, and, finally, with worse self-reported health status and shorter length of hospital stay.

Conclusion: The findings from this study add to the evidence and the urgency of developing and implementing effective interventions to improve delivery of health care at the community level and provided support to the usefulness of avoidable hospitalizations for ACSCs to monitor this process. 


\section{Background}

Ambulatory care-sensitive conditions (ACSC), such as hypertension, diabetes, chronic heart failure, chronic obstructive pulmonary disease and asthma, are conditions that can be managed with timely and effective outpatient care reducing the need of hospitalization. Rates of avoidable hospitalizations, also called preventable hospitalizations, for ACSC have been used to assess access, quality and performance of the primary care delivery system. This includes primary prevention, early detection and monitoring of acute episodes and follow-up and monitoring of chronic conditions.

The Agency for Healthcare Research and Quality (AHRQ) developed the Preventive Quality Indicators (PQIs), a set of measures to identify ACSC as rates of admission to the hospital based on the assumption that high hospitalization rates for ACSC may result from poor access to primary care and can be prevented [1]. ACSC have been evaluated in many countries most in the US but also in Australia, Canada and European countries [2-5] for determining the socioeconomic and medical conditions associated with hospitalized ACSC [6-12]; however, little is known about role of access to primary care, measured as number of accesses, number of patients per primary care physician (PCP), health care seeking and physician practice style [13-17].

In Italy, where universal and free access to primary health care is provided through the National Health Service, these indicators can serve as a convenient and effective evaluation tool to assess effectiveness of and barriers to access to primary care. Community health care is provided by health districts, geographical units responsible for coordinating and providing primary care, pharmaceuticals, home care, specialist and residential and semi-residential care. Primary care is provided by physicians and pediatricians working under government contract, who are paid a capitation fee based on the number of patients (adults or children) on their list with a maximum number of patients allowed (1500-1800 for general practitioners and 800-1000 for pediatricians). The PCPs act as "gatekeepers" for access to secondary services and this role has a great impact both on quality of outcomes and cost of healthcare, but for several reasons patients prefer to attend specialists or hospitals [18].

The aims of this study were to quantify the proportion of avoidable hospital admissions for ACSCs, to identify the related patient's socio-demographic profile and health conditions, to assess whether barriers to access to primary care were related to preventable hospitalizations in Italy and to assess the usefulness of avoidable hospitalizations for ACSCs to monitor the effectiveness of primary health care.

\section{Methods \\ Study population}

This cross-sectional study was conducted from April to July 2005 by reviewing a random sample of 520 medical records of patients aged 18 and over admitted to medical wards (Cardiology, Internal Medicine, Pneumology, Geriatrics) of a non-teaching acute care 717-bed hospital located in Catanzaro (Italy).

Two physicians, who were not involved in care and who had been previously trained, collected the data by reviewing charts and by interviewing at bedside all the patients who agreed to participate, independently. Actual data collection and extraction did not start until the performance of the reviewers had been judged satisfactory and showed satisfactory inter-rater reliability. The analysis on medical records was based on data reviewed by both physicians in which discrepancies were solved through discussion among reviewers.

A total of 492 patients agreed to participate and were enrolled for a response rate of $94.6 \%$, thus minimizing the role of non-respondent bias.

\section{Review instrument}

The following data were collected for each patient by reviewing charts: socio-demographics (age, gender, marital status, education level), distance of patient's home from hospital, Charlson et al. comorbidity index [19], ward and type of admission, and who referred the patient to the hospital. The following data were collected by interviewing at bedside all the patients who agreed to participate: socio-demographics (working activity, number of persons in the household), the self-reported health status, self-reported utilization of health services during the previous year (propensity to seek care, number and main reasons of visit and for not having been to a PCP medical visit, difficulty to the access to and satisfaction with PCP health services, number and main reasons for specialist visit, emergency access, hospital admission), and the name of their own PCP. The questionnaire focused particularly on frequency of utilization of health services during the previous year with most questions in "yes/no" format. If the answer was "yes" then the participants were asked the number of accesses. The questions on satisfaction and difficulty with PCP health services were scored on a fourpoint Likert scale with options for no, few, rather, and much. The questionnaire was pretested on a sample to ensure clarity of interpretation to improve the validity of responses. The accuracy of patient self-report of health services utilization is of paramount concern, however such data is often used to estimate health care utilization and have demonstrated to be a reasonably accurate method to obtain information on most types of medical utilization in the general population [20-22]. 
We selected 9 out of 16 PQIs from AHRQ, defined by diagnosis and procedure codes of International Classification of Diseases (ICD-9-CM) [23], to identify the preventable hospitalizations for ACS conditions: diabetes shortterm and long-term complication, uncontrolled diabetes, chronic obstructive pulmonary disease, hypertension, congestive heart failure, bacterial pneumonia, angina without procedure and adult asthma. We excluded pediatric indicators (pediatric asthma, pediatric gastroenteritis, low birth weight) and indicators for adult conditions that were rarely encountered, in our setting, as discharge diagnosis, as measured by reviewing discharge records in the previous two years (perforated appendix, dehydration, urinary tract infection, lower-extremity amputation among patients with diabetes). Assessment of avoidable hospitalizations was made by using the discharge data according to the Guide to Prevention Quality Indicators from AHRQ [1].

The Ethics Committee of the "Mater Domini" Hospital of Catanzaro (Italy) approved the protocol of the study (Prot. E.C. $\left.n^{\circ} 16 / 2005\right)$.

\section{Statistical analysis}

A multivariate logistic regression analysis was performed to identify baseline characteristics independently associated with the following outcomes of interest: preventable hospitalization for all investigated conditions, preventable hospitalization for cardiovascular diseases (hypertension, congestive heart failure, angina without procedure), preventable hospitalization for respiratory diseases (chronic obstructive pulmonary disease, bacterial pneumonia, adult asthma), preventable hospitalization for diabetes (diabetes short-term complication, diabetes long-term complication, uncontrolled diabetes). Model building strategy and particularly ways to include independent variables in the model (continuous, ordinal or categorical) took into account how each of these ways better fitted the data at the univariate analysis and we chose that way in the multivariate analysis. Moreover, as regards to the cut-off points for less or more than 12 accesses or visits per year, our idea was that in many chronic patients, one access per month is generally useful for monitoring chronic conditions. In all models the explanatory variables included were the following: patient's age (continuous), patient's sex (male $=0$, female $=1$ ), distance in kilometers between patient's home and hospital (continuous), educational level (no formal education $=0$, primary school $=1$, secondary school or higher $=2$ ), living condition (with family $=1$, other $=2$ ), additional persons in the household (none $=0,1=1,>1=2$ ), working activity (retired $=0$, other $=1$ ), type of admission (emergency physician $=1$, other $=2$ ), length of hospital stay (continuous), age-adjusted Charlson et al. comorbidity index (continuous), self-reported health status on a 10 points scale $(\leq 4=0, \geq 5=1)$, number of PCP accesses in the pre- vious year $(\leq 12=1,>12=2)$, number of PCP medical visits in the previous year $(\leq 12=1,>12=2)$, satisfaction with PCP health services $($ no/few $=0$, rather $/$ much $=1)$, number of patients for each PCP $(<1000=1,1000-1300$ $=2,>1300=3$ ), number of specialist visits in community health services (none $=0, \geq 1=1$ ), number of emergency accesses in the previous year (none $=0, \geq 1=1$ ), and number of hospital admissions in the previous year (none $=0, \geq 1=1)$. The significance level for variables entering the logistic regression models was set at 0.2 and for removing from the model at 0.4 . Adjusted odds ratio (ORs) and 95\% confidence intervals (CIs) were calculated. The data were analyzed using the Stata software program [24].

\section{Results}

The main characteristics of the study population are presented in Table 1. Fifty-two per cent were females, the median age was 75 years (range 23-95), and three quarters lived with their family, more than half were in general medical wards $(68.3 \%)$, the median length of stay was 9 days (range 1-83) and the median of Charlson et al. comorbidity index was 4 (range 0-14). Almost all (99.2\%) had at least one PCP access in the previous year, more than $40 \%$ had at least one hospital admission in the previous year, and at least one district health services access. More than $70 \%$ were satisfied with PCP health services, and the main reasons for dissatisfaction were long waiting times for access (18.2\%), opening hours $(11.7 \%)$, and trust in hospital physicians $(7.4 \%)$. Overall, $17.2 \%$ reported difficulty of access to PCP health services.

In the study period, a total of $31.5 \%$ of the hospitalizations in the sample were judged to be preventable. Of these, $40 \%$ were for congestive heart failure, $23.2 \%$ for chronic obstructive pulmonary disease, $13.5 \%$ for angina without procedure, $8.4 \%$ for hypertension, $7.1 \%$ for bacterial pneumonia, $3.2 \%$ for diabetes short-term complication, $2.6 \%$ for adult asthma, $1.3 \%$ for diabetes long-term complication and $0.6 \%$ for uncontrolled diabetes.

Patients admitted for a preventable hospitalization were more frequently males ( $58.1 \%$ vs. $43.3 \%$ ), older (median age 76 vs. 74 ), with a higher unsatisfactory self-reported health status $(56.1 \%$ vs. $36.8 \%)$, reported more frequently less than 13 PCP medical visits ( $93.5 \%$ vs. $47.9 \%)$ and less than 13 PCP accesses (41.6\% vs. $19.5 \%$ ) in the previous year, attended a PCP with a higher number of patients $(65.6 \%$ vs. $31.1 \%)$, were more frequently unsatisfied by PCP health services (54\% vs. $15.6 \%$ ), and were more likely to have had at least one emergency access (52.6\% vs. $45.2 \%$ ) and hospital admission in the previous year ( $54 \%$ vs. $40.1 \%)$.

Preventable hospitalizations were significantly associated with age and sex since they were higher in older patients 
Table I: Selected characteristics of the study population

\begin{tabular}{|c|c|c|}
\hline Characteristic & $\mathrm{N}^{*}$ & $\%$ \\
\hline \multicolumn{3}{|l|}{ Sex } \\
\hline Male & 236 & 48 \\
\hline Female & 256 & 52 \\
\hline \multicolumn{3}{|l|}{ Age group, years } \\
\hline$<65$ & 106 & 21.5 \\
\hline $65-74$ & 139 & 28.3 \\
\hline $75-84$ & 196 & 39.8 \\
\hline$\geq 85$ & 51 & 10.4 \\
\hline Median & 75 & \\
\hline \multicolumn{3}{|l|}{ Education level } \\
\hline No formal education & 177 & 36 \\
\hline Primary school & 186 & 37.8 \\
\hline Secondary school or higher & 129 & 26.2 \\
\hline \multicolumn{3}{|l|}{ Marital status } \\
\hline Married & 286 & 58.1 \\
\hline Others & 206 & 41.9 \\
\hline \multicolumn{3}{|l|}{ Living condition } \\
\hline With family & 368 & 74.8 \\
\hline Other & 124 & 25.2 \\
\hline \multicolumn{3}{|c|}{ Additional persons in the household } \\
\hline None & 110 & 22.4 \\
\hline 1 & 205 & 41.6 \\
\hline$>1$ & 177 & 36 \\
\hline \multicolumn{3}{|l|}{ Working activity } \\
\hline Retired & 411 & 83.5 \\
\hline Other & 81 & 16.5 \\
\hline \multicolumn{3}{|c|}{ Distance from home to hospital, $\mathrm{km}$} \\
\hline$\leq 5$ & 227 & 46.1 \\
\hline $6-35$ & 153 & 31.1 \\
\hline$>35$ & 112 & 22.8 \\
\hline Median & 20 & \\
\hline \multicolumn{3}{|l|}{ Type of admission } \\
\hline Emergency physician & 432 & 87.8 \\
\hline Other & 60 & 12.2 \\
\hline \multicolumn{3}{|l|}{ Length of hospital stay, days } \\
\hline Median & 9 & \\
\hline \multicolumn{3}{|c|}{ Age-adjusted Charlson et al. comorbidity index } \\
\hline Median & 4 & \\
\hline \multicolumn{3}{|c|}{ Self-reported health status on a 10 points scale } \\
\hline$\leq 4$ & 211 & 42.9 \\
\hline$\geq 5$ & 281 & 57.1 \\
\hline \multicolumn{3}{|l|}{$\mathrm{PCP}$ accesses in the previous year } \\
\hline None & 4 & 0.8 \\
\hline $1-12$ & 129 & 26.2 \\
\hline$>12$ & 359 & 73 \\
\hline \multicolumn{3}{|c|}{ PCP medical visits in the previous year } \\
\hline$\leq 12$ & 304 & 62.3 \\
\hline$>12$ & 184 & 37.7 \\
\hline Satisfaction with PCP health ser & & \\
\hline No/few & 135 & 27.7 \\
\hline Rather/much & 353 & 72.3 \\
\hline Difficulty of access to PCP healt & & \\
\hline No/few & 404 & 82.8 \\
\hline Rather/much & 84 & 17.2 \\
\hline Patients for each PCP & & \\
\hline$<1000$ & 146 & 29.9 \\
\hline $1000-1300$ & 137 & 28.1 \\
\hline$>1300$ & 205 & 42 \\
\hline District health services accesses & & \\
\hline None & 310 & 63.5 \\
\hline$\geq 1$ & 178 & 36.5 \\
\hline Emergency accesses in the previ & & \\
\hline None & 260 & 52.8 \\
\hline$\geq 1$ & 232 & 47.2 \\
\hline Hospital admissions in the previ & & \\
\hline None & 275 & 55.9 \\
\hline$\geq 1$ & 217 & 44.1 \\
\hline
\end{tabular}

*The numbers that do not add to 492 are due to not applicable data for the variable.

PCP, primary care physician.
$(\mathrm{OR}=1.03,95 \% \mathrm{CI}=1.01-1.05, \mathrm{p}=0.027)$ and in males $(\mathrm{OR}=0.52,95 \% \mathrm{CI}=0.31-0.87, \mathrm{p}=0.013)$. The proportion of patients who had a preventable hospitalization significantly increased with regard to the number of hospital admissions in the previous year $(\mathrm{OR}=1.76,95 \% \mathrm{CI}$ $=1.06-2.93, \mathrm{p}=0.03)$ and to the number of patients for each PCP $(\mathrm{OR}=2.25,95 \% \mathrm{CI}=1.62-3.13, \mathrm{p}<0.001)$, with lower number of PCP accesses $(\mathrm{OR}=0.52,95 \% \mathrm{CI}=$ $0.3-0.93, \mathrm{p}=0.027)$ and PCP medical visits in the previous year $(\mathrm{OR}=0.1,95 \% \mathrm{CI}=0.05-0.23, \mathrm{p}<0.001)$, with less satisfaction about PCP health services $(\mathrm{OR}=0.34$, $95 \% \mathrm{CI}=0.2-0.58, \mathrm{p}<0.001)$, and, finally, with worse self-reported health status $(\mathrm{OR}=0.53,95 \% \mathrm{CI}=0.31-$ $0.89, \mathrm{p}=0.017)$ and shorter length of hospital stay $(\mathrm{OR}=$ $0.95,95 \% \mathrm{CI}=0.91-0.99, \mathrm{p}=0.011$ ) (Model 1 in Table 2).

Preventable hospitalizations for cardiovascular diseases were significantly more common for higher number of patients for each PCP $(\mathrm{OR}=2.2,95 \% \mathrm{CI}=1.5-3.22, \mathrm{p}<$ 0.001 ) and for lower number of PCP accesses ( $\mathrm{OR}=0.52$, $95 \% \mathrm{CI}=0.27-0.98, \mathrm{p}=0.044)$ and PCP medical visits $(\mathrm{OR}=0.12,95 \% \mathrm{CI}=0.05-0.3, \mathrm{p}<0.001)$ in the previous year. Moreover patients who had a preventable hospitalization for cardiovascular diseases were significantly more likely to be less satisfied for PCP health services (OR = $0.31,95 \% \mathrm{CI}=0.17-0.57, \mathrm{p}<0.001)$, retired $(\mathrm{OR}=0.37$, $95 \% \mathrm{CI}=0.13-0.97, \mathrm{p}=0.044)$, with worse self-reported health status $(\mathrm{OR}=0.5,95 \% \mathrm{CI}=0.27-0.93, \mathrm{p}=0.027)$ and shorter length of hospital stay $(\mathrm{OR}=0.94,95 \% \mathrm{CI}=$ 0.9-0.99, $\mathrm{p}=0.013$ ) (Model 2 in Table 2).

Preventable hospitalizations for respiratory diseases were significantly associated with higher number of patients for each PCP $(\mathrm{OR}=2.86,95 \% \mathrm{CI}=1.66-4.94, \mathrm{p}<0.001)$ and emergency accesses in the previous year $(\mathrm{OR}=2.71,95 \%$ $\mathrm{CI}=1.2-6.11, \mathrm{p}=0.016)$, with males $(\mathrm{OR}=0.27,95 \% \mathrm{CI}$ $=0.11-0.64, \mathrm{p}=0.003)$, worse satisfaction for PCP health services $(\mathrm{OR}=0.27,95 \% \mathrm{CI}=0.13-0.58, \mathrm{p}=0.001)$ and lower number of PCP accesses $(\mathrm{OR}=0.34,95 \% \mathrm{CI}=$ $0.14-0.82, \mathrm{p}=0.017$ ) and PCP medical visits ( $\mathrm{OR}=0.11$, $95 \%$ CI $=0.03-0.4, \mathrm{p}=0.001)$ in the previous year (Model 3 in Table 2).

Finally, preventable hospitalizations for diabetes were significantly higher with the number of hospital admissions in the previous year $(\mathrm{OR}=9.74,95 \% \mathrm{CI}=1.14-83.39, \mathrm{p}$ $=0.038)$ and the number of patients for each PCP (OR = $4.75,95 \% \mathrm{CI}=1.22-18.48, \mathrm{p}=0.025$ ) (Model 4 in Table 2).

\section{Discussion}

One of the main findings of our study was that more than $30 \%$ of the hospitalizations were considered preventable according to the PQI indicators. Although most of the 
Table 2: Logistic regression models results 1,2

\begin{tabular}{|c|c|c|c|c|}
\hline Variable & OR & SE & $95 \% \mathrm{Cl}$ & $\mathrm{P}$ \\
\hline \multicolumn{5}{|c|}{ Model I. Outcome: Overall preventable hospitalization } \\
\hline \multicolumn{5}{|c|}{ Log-likelihood $=-194.19, \chi^{2}=220.14, p<0.001$, Number of observations $=488$} \\
\hline Number of PCP medical visits in the previous year & 0.1 & 0.04 & $0.05-0.23$ & $<0.001$ \\
\hline Number of patients for each PCP & 2.25 & 0.38 & $1.62-3.13$ & $<0.001$ \\
\hline Satisfaction with PCP health services & 0.34 & 0.09 & $0.2-0.58$ & $<0.001$ \\
\hline Length of hospital stay & 0.95 & 0.02 & $0.91-0.99$ & 0.011 \\
\hline Sex & 0.52 & 0.14 & $0.3 \mathrm{I}-0.87$ & 0.013 \\
\hline Self-reported health status & 0.53 & 0.14 & $0.31-0.89$ & 0.017 \\
\hline Number of $\mathrm{PCP}$ accesses in the previous year & 0.52 & 0.15 & $0.3-0.93$ & 0.027 \\
\hline Age & 1.03 & 0.01 & $1.01-1.05$ & 0.027 \\
\hline Number of hospital admissions in the previous year & 1.76 & 0.46 & $1.06-2.93$ & 0.03 \\
\hline Additional persons in the household & 0.75 & 0.13 & $0.53-1.06$ & 0.105 \\
\hline Type of admission & 0.57 & 0.24 & $0.25-1.3$ & 0.18 \\
\hline Distance between patient's home and hospital & 0.99 & 0.01 & $0.98-1.01$ & 0.399 \\
\hline \multicolumn{5}{|c|}{$\begin{array}{l}\text { Model 2. Outcome: Preventable hospitalization for cardiovascular diseases } \\
\text { Log-likelihood }=-150.13, \chi^{2}=\mid 53.38, p<0.001 \text {, Number of observations }=429\end{array}$} \\
\hline Number of patients for each PCP & 2.2 & 0.43 & $1.5-3.22$ & $<0.001$ \\
\hline Satisfaction with PCP health services & 0.31 & 0.09 & $0.17-0.57$ & $<0.001$ \\
\hline Number of PCP medical visits in the previous year & 0.12 & 0.06 & $0.05-0.3$ & $<0.001$ \\
\hline Length of hospital stay & 0.94 & 0.02 & $0.9-0.99$ & 0.013 \\
\hline Self-reported health status & 0.5 & 0.16 & $0.27-0.93$ & 0.027 \\
\hline Number of $\mathrm{PCP}$ accesses in the previous year & 0.52 & 0.17 & $0.27-0.98$ & 0.044 \\
\hline Working activity & 0.37 & 0.18 & $0.13-0.97$ & 0.044 \\
\hline Sex & 0.62 & 0.18 & $0.35-1.1$ & 0.106 \\
\hline Number of hospital admissions in the previous year & 1.53 & 0.46 & $0.85-2.77$ & 0.156 \\
\hline Additional persons in the household & 0.76 & 0.15 & $0.51-1.13$ & 0.172 \\
\hline Age-adjusted Charlson et al. comorbidity index & 1.08 & 0.07 & $0.96-1.22$ & 0.19 \\
\hline \multicolumn{5}{|c|}{ Model 3. Outcome: Preventable hospitalization for respiratory diseases } \\
\hline \multicolumn{5}{|c|}{ Log-likelihood $=-92.36, \chi^{2}=116.38, p<0.001$, Number of observations $=385$} \\
\hline Number of patients for each PCP & 2.86 & 0.8 & $1.66-4.94$ & $<0.001$ \\
\hline Satisfaction with PCP health services & 0.27 & 0.11 & $0.13-0.58$ & 0.001 \\
\hline Number of PCP medical visits in the previous year & 0.11 & 0.07 & $0.03-0.4$ & 0.001 \\
\hline Sex & 0.27 & 0.12 & $0.11-0.64$ & 0.003 \\
\hline Number of emergency accesses in the previous year & 2.71 & 1.12 & $1.2-6.11$ & 0.016 \\
\hline Number of PCP accesses in the previous year & 0.34 & 0.15 & $0.14-0.82$ & 0.017 \\
\hline Type of admission & 0.2 & 0.17 & $0.04-1.05$ & 0.058 \\
\hline Living condition & 2.35 & 1.08 & $0.95-5.81$ & 0.063 \\
\hline Self-reported health status & 0.49 & 0.21 & $0.21-1.12$ & 0.092 \\
\hline Age & 1.03 & 0.02 & $0.99-1.07$ & 0.131 \\
\hline Age-adjusted Charlson et al. comorbidity index & 0.88 & 0.08 & $0.73-1.05$ & 0.159 \\
\hline Length of hospital stay & 0.97 & 0.03 & $0.92-1.02$ & 0.232 \\
\hline \multicolumn{5}{|c|}{$\begin{array}{l}\text { Model 4. Outcome: Preventable hospitalization for diabetes } \\
\text { Log-likelihood }=-21.54, \chi^{2}=18.77, p=0.0277, \text { Number of observations }=144\end{array}$} \\
\hline Number of patients for each PCP & 4.75 & 3.29 & $1.22-18.48$ & 0.025 \\
\hline Number of hospital admissions in the previous year & 9.74 & 10.67 & $1.14-83.39$ & 0.038 \\
\hline Number of PCP accesses in the previous year & 0.15 & 0.17 & $0.02-1.34$ & 0.090 \\
\hline Education level & 0.27 & 0.23 & $0.05-1.46$ & 0.129 \\
\hline Length of hospital stay & 0.88 & 0.09 & $0.72-1.08$ & 0.216 \\
\hline Number of specialist visits in community health services & 0.36 & 0.37 & $0.05-2.79$ & 0.326 \\
\hline Self-reported health status & 2.61 & 2.57 & $0.38-18$ & 0.332 \\
\hline Sex & 2.47 & 2.33 & $0.39-15.65$ & 0.338 \\
\hline Age & 1.04 & 0.05 & $0.95-1.14$ & 0.340 \\
\hline
\end{tabular}

ISignificance level is set at $\mathrm{p} \leq 0.05$

2The variables are presented in order of decreasing significance.

$\mathrm{PCP}$, primary care physician. 
studies conducted on this topic used hospitalization rates $[13,25-30]$, investigations on prevalence of avoidable hospitalizations showed variable results ranging from 5.9\% in the USA considering 12 ACS conditions [31] to 34\% in the same country [30]. Therefore, our prevalence is one of the highest encountered in the literature and deserves detailed comments. It has been argued that hospital admissions rates for ACSC alone are not sufficient proof that the provision of ambulatory care is inadequate, since some hospitalizations for ACSC will occur only because some ACSC are less manageable than others. Moreover, higher proportions of ACSCs may reflect higher prevalence for those particular diseases in the population. However, prevalence of the chronic diseases evaluated in our study is not substantially different from that encountered in most European countries, and we strongly believe that the high prevalence of admissions for ACSCs is related to unsatisfactory access and delivery of primary care, which leads to deterioration of health conditions and to overutilization of hospitals. Indeed, this conclusion has already been adduced in a survey conducted by some of us to assess satisfaction with PCPs which showed that many patients prefer to seek assistance at a more sophisticated level of care [18]. Moreover, we investigated emergency department use and hospitalization in the prior year as very interesting indicators of PCP access problems. Indeed, findings of a previous study conducted by some of us in the same area, regarding the utilization of the emergency department as a source of non-urgent care indicated high overutilization of the department and that patients were self-referred or referred by relatives to the emergency department [32]. This observation emphasizes that, although all patients in our national health care system have a general practitioner who should provide primary care, the emergency department is used as a primary health care facility and, therefore, this prevents general practitioners from playing an effective role in the patient management and as an interface between hospital and community based services. As a consequence, we agree that the health of patients with certain chronic medical conditions deteriorates without access to regular medical care and that this decline contributes to increased use of emergency departments and ultimately to increased hospitalizations [33,34]. Programs to improve the access and quality of primary care have notably reduced emergency department visits. Results of such programs suggest that areas with high levels of emergency department visits may have less access to primary care, and therefore poorer population health [35].

We found that avoidable hospitalizations are more likely to have a shorter length of stay. We have tested this association, since in previous studies performed in our area, high inappropriateness of hospital use was found and we believe that for chronic conditions in many cases this could happen also for avoidable hospitalizations and indeed inappropriate admissions have generally shorter length of stay [36].

Almost all prior studies have computed rates from databases, and factors not contained such as variations in disease prevalence, health care seeking behavior, and physician practice style could also affect preventable hospitalization rates [13], and it has been reported that the study of predictors of ACSC hospitalizations should have been applied to individual-level data [17]. We examined preventable hospitalizations in individual patients, comparing subjects admitted for ACSC conditions to those admitted for other reasons, and this strategy allowed us to identify the independent effects of various factors, pertaining to subjects' characteristics and primary care supply, on the probability of ACSC admissions.

Regarding subjects' demographic and social characteristics we found that older males were more likely to be hospitalized for ACSCs, whereas no other socio-demographic feature tested predicted ACSCs. Preventable hospitalizations have been associated with lower socioeconomic status, advanced age, poor health and higher education [37], since people with higher levels of education are likely to have greater awareness and knowledge of the local health care system and a better knowledge of disease processes, and may therefore seek medical treatment earlier. In our study education did not influence admissions for ACSCs, whereas, as in a previous study [38], perceived poor health status was indeed a significant predictor of hospitalization for ACSCs.

Primary care access measures, such as satisfaction with PCP health services and number of patients per PCP, as well as proxies of propensity to seek care, such as number of accesses and visits to PCPs in the previous year, were all related to hospitalization for ACSCs. Our results indicate that poor access to primary health care increases the likelihood of hospitalization for ACSCs, after controlling for most of the other factors that may affect hospital admission, such as socio-demographics and propensity to seek care. Some of the variables included in the model, such as number of PCP accesses and visits in the previous year, number of patients per PCP and satisfaction with PCP services, may be highly correlated; therefore we calculated some selected correlation coefficients and we found that, as expected, number of PCP accesses and PCP visits were significantly correlated $(\mathrm{r}=0.46, \mathrm{p}<0.001)$ and satisfaction with PCP services was significantly correlated to number of PCP visits $(\mathrm{r}=0.30, \mathrm{p}<0.001)$, whereas number of patients per PCP was inversely correlated to number of PCP visits $(r=-0.17, \mathrm{p}<0.001)$ and satisfaction with PCP health services $(\mathrm{r}=-0.19, \mathrm{p}<0.001)$. To assess the role of each of these variables independently 
from others, we included all of them into the logistic regression model. Therefore, we believe that our results strongly support the validity of ACSCs as an indicator of quality of primary care and confirm the crucial role of PCPs in reducing unnecessary hospitalizations. Similar findings have been reported by Zhan et al., who showed that living in a primary care shortage area or in a higher supply of hospital beds area represented independent risk factor for a preventable hospitalization, even after controlling for other socio-demographic characteristics associated with health care use [37]. Moreover, adults identified as having a PCP were four times more likely to be discharged with a non-ACSC diagnosis compared to those without a PCP [17].

We collected data in one hospital and concern about generalizability of our results may arise. However, although very scarce data is available in Italy on ACSCs, it seems, as for many other health services indicators, that there are differences between Northern and Southern Italy. In a recent report from the Observatory of the Health of the Italian Regions, avoidable hospitalization rates were similar in Southern regions and consistently higher as compared to Northern regions [39]. For example, for adult asthma the preventable hospitalization rates in Southern Italy ranged from 0.27 discharges/1.000 inhabitants in Campania and Sicily to 0.45 discharges/ 1.000 inhabitants in Sardinia (Calabria region has a rate of 0.35 discharges/ 1.000 inhabitants). In the centre and in the north of Italy rates ranged from 0.13 discharges/1.000 inhabitants in Valle d'Aosta to 0.33 discharges/1.000 inhabitants in Bozen's autonomous administration, whereas the overall national rate is 0.24 discharges/1.000 inhabitants [39]. Therefore, although we cannot exclude that our results pertain only to our area, it is reasonable to suppose that an analogous context may be referred to the Southern part of our country. To have more insight into provision of primary care in other areas as measured by avoidable hospitalization, we strongly suggest replication of the study in other regions of the country.

Most Western countries are facing tremendous transformations in their healthcare systems, and one main element of change concerns the transition from an inpatient hospital-centered health care system to a multi level community-spread healthcare system that allows selection of health conditions that can be treated only in hospital. However, this transition is far from being completely implemented in Italy and our findings confirm that improvement of access to primary care may reduce avoidable hospitalizations. Therefore, our results have significant implications for health care policymakers, since ACSCs may be useful to monitor effectiveness and to reduce barriers to access to primary health care.

\section{Conclusion}

In conclusion, the findings from this study add to the evidence and the urgency of developing and implementing effective interventions to improve delivery of health care at the community level and provided support to the usefulness of avoidable hospitalizations for ACSCs to monitor this process.

\section{Competing interests}

The author(s) declare that they have no competing interests.

\section{Authors' contributions}

$\mathrm{PR}$ and $\mathrm{AB}$ participated in the design of the study, collected the data, and contributed to the data analysis and interpretation. MP designed the study, the data analysis and interpretation, and wrote the article. IFA designed the study, the data analysis and interpretation, and gave final approval of the version to be published.

All authors read and approved the final manuscript.

\section{Acknowledgements}

At the time of this study Italo F. Angelillo was with the Chair of Hygiene, Medical School, University of Catanzaro "Magna Græcia", Catanzaro (Italy)

\section{References}

I. Agency for Healthcare Research and Quality: AHRQ Quality Indicators - Guide to Prevention Quality Indicators: Hospital Admission for Ambulatory Care Sensitive Conditions. Revision 4. Rockville, MD, Agency for Healthcare Research and Quality; 2004.

2. Ansari Z, Barbetti T, Carson NJ, Auckland MJ, Cicuttini F: The Victorian ambulatory care sensitive conditions study: rural and urban perspectives. Soz Praventivmed 2003, 48:33-43.

3. Sanderson C, Dixon J: Conditions for which onset or hospital admission is potentially preventable by timely and effective ambulatory care. J Health Serv Res Policy 2000, 5:222-230.

4. Roos LL, Walld R, Uhanova J, Bond R: Physician visits, hospitalizations, and socioeconomic status: ambulatory care sensitive conditions in a Canadian setting. Health Serv Res 2005, 40: I I67-II85.

5. Bermudez-Tamayo C, Marquez-Calderon S, Rodriguez del Aguila MM, Perea-Milla Lopez E, Ortiz Espinosa J: Organizational characteristics of primary care and hospitalization for to the main ambulatory care sensitive conditions. Aten Primaria 2004, I5:305-3|I.

6. Caminal J, Starfield B, Sanchez E, Casanova C, Morales M: The role of primary care in preventing ambulatory care sensitive conditions. Eur J Public Health 2004, I 4:246-25I.

7. Zeng F, O'Leary JF, Sloss EM, Lopez MS, Dhanani N, Melnick G: The effect of Medicare Health Maintenance Organizations on hospitalization rates for Ambulatory Care-Sensitive Conditions. Med Care 2006, 44:900-907.

8. Gaskin DJ, Hoffman C: Racial and ethnic differences in preventable hospitalizations across 10 states. Med Care Res Rev 2000, 57(suppl I):85-107.

9. Laditka JN: Hazards of hospitalization for ambulatory care sensitive conditions among older women: evidence of greater risks for African Americans and Hispanics. Med Care Res $\operatorname{Rev} 2003$, 60:468-495.

10. Laditka JN, Laditka SB: Race, ethnicity and hospitalization for six chronic ambulatory care sensitive conditions in the USA. Ethn Health 2006, I I:247-263.

II. Parchman ML, Culler S: Preventable hospitalisations in primary care shortage areas. Arch Fam Med 1999, 8:487-49I. 
12. Ricketts TC, Randolph R, Howard HA, Pathman D, Carey T: Hospitalization rates as indicators of access to primary care. Health Place 2001, 7:27-38.

13. Bindman AB, Grumbach K, Osmond D, Komaromy M, Vranizan K, Lurie N, Billings J, Stewart A: Preventable hospitalisations and access to health care. JAMA 1995, 274:305-3II.

14. Epstein AJ: The role of public clinics in preventable hospitalizations among vulnerable populations. Health Serv Res 200I, 36:405-420.

15. Gill JM, Mainous AG III: The role of provider continuity in preventing hospitalizations. Arch Fam Med 1998, 7:352-357.

16. Billings J, Teicholz N: Uninsured patients in District of Columbia hospitals. Health Aff 1990, 9:158-165.

17. Shi L, Samuels ME, Pease M, Bailey WP, Corley EH: Patient characteristics associated with hospitalizations for ambulatory care sensitive conditions in South Carolina. South Med J 1999, 92:989-998.

18. Pavia M, Carbone V, Pileggi C, Angelillo IF: Patients' perceptions and related behaviours on role of primary care physician in Italy. Eur J Public Health 2004, I 4:258-260.

19. Charlson ME, Pompei P, Ales KL, MacKenzie CR: A new method of classifying prognostic comorbidity in longitudinal studies: development and validation. J Chronic Dis 1987, 40:373-383.

20. Bhandari A, Wagner T: Self-reported utilization of health care services: improving measurement and accuracy. Med Care Res Rev 2006, 63:217-235.

21. Reijneveld SA, Stronks K: The validity of self-reported use of health care across socioeconomic strata: a comparison of survey and registration data. Int I Epidemiol 200I, 30:|407-|4| 4.

22. Lubeck DP, Hubert HB: Self-report was a viable method for obtaining health care utilization data in community-dwelling seniors. J Clin Epidemiol 2005, 58:286-290.

23. World Health Organization: International classification of disease 9th Revision edition. Geneva, Switzerland; 1997.

24. Stata Corporation: Stata Statistical Software: Release 8.I. College Station, TX. Stata Corp; 2003.

25. Billings ], Anderson GM, Newman LS: Recent findings on preventable hospitalizations. Health Aff 1996, 15:239-249.

26. Billings J, Zeitel L, Lukomnik J, Carey TS, Blank AE, Newman L: Impact of socioeconomic status on hospital use in New York City. Health Aff 1993, I 2:162-173.

27. Davis SK, Liu Y, Gibbons GH: Disparities in trends of hospitalization for potentially preventable chronic conditions among African Americans during the 1990s: implications and benchmarks. Am J Public Health 2003, 93:447-455.

28. Niti M, Ng TP: Avoidable hospitalisation rates in Singapore, 199 I-1998: assessing trends and inequities of quality in primary care. J Epidemiol Community Health 2003, 57:17-22.

29. Pappas G, Hadden WC, Kozak LJ, Fisher GF: Potentially avoidable hospitalizations: inequalities in rates between US socioeconomic groups. Am J Public Health 1997, 87:8II-8I6.

30. Backus L, Moron M, Bacchetti P, Baker LC, Bindman AB: Effect of managed care on preventable hospitalization rates in California. Med Care 2002, 40:315-324.

31. Kozak LJ, Hall MJ, Owings MF: Trends in avoidable hospitalizations, 1980-1998. Health Aff 200I, 20:225-232.

32. Bianco A, Pileggi C, Angelillo IF: Non-urgent visits to a hospital emergency department in Italy. Public Health 2003, I I 7:250-255.

33. Grossman LK, Rich LN, Johnson C: Decreasing nonurgent emergency department utilization by medicaid children. Pediatrics 1998, 102:20-24.

34. Zuckerman S, Brennan N, Yemane A: Has medicaid managed care affected beneficiary access and use? Inquiry 2002, 39:22I-242.

35. Laditka JN, Laditka SB, Probst JC: More may be better: evidence of a negative relationship between physician supply and hospitalization for ambulatory care sensitive conditions. Health Serv Res 2005, 40: I148-1166.

36. Angelillo IF, Ricciardi G, Nante N, Boccia A, Collaborative Group: Appropriateness of hospital utilisation in Italy. Public Health 2000, II 14:9-14

37. Zhan C, Miller MR, Wong H, Meyer GS: The effects of HMO penetration on preventable hospitalizations. Health Serv Res 2004, 39:345-361.
38. Blustein J, Hanson K, Shea S: Preventable hospitalizations and socioeconomic status. Health Aff 1998, 17:177-189.

39. Osservatorio Nazionale sulla Salute nelle Regioni Italiane: Rapporto Osservasalute 2006. Milano 2006.

\section{Pre-publication history}

The pre-publication history for this paper can be accessed here:

http://www.biomedcentral.com/1472-6963/7/134/pre pub

Publish with Biomed Central and every scientist can read your work free of charge

"BioMed Central will be the most significant development for disseminating the results of biomedical research in our lifetime. "

Sir Paul Nurse, Cancer Research UK

Your research papers will be:

- available free of charge to the entire biomedical community

- peer reviewed and published immediately upon acceptance

- cited in PubMed and archived on PubMed Central

- yours - you keep the copyright 